\title{
WTP for Luxury EVs and their Attributes: A Bayesian Approach to Highlight the Ecology Effect on DM
}

\author{
Houssam Jedidi ${ }^{1 *}$ and Oliver Heil ${ }^{2}$ \\ ${ }^{1}$ Department of Marketing, Johannes Gutenberg University of Mainz, Germany \\ ${ }^{2}$ Cahir of Marketing at Gutenberg University of Mainz, Germany
}

*Corresponding author: Houssam Jedidi, Johannes Gutenberg University of Mainz, Marketing Department (Prof. Dr. Oliver P. Heil (PhD.)), Jackob-Welder Weg. 9, Mainz, Rheinland-Pfalz, Germany.

Received Date: July 24, 2019

Published Date: August 05, 2019

Abstract

Environmental friendliness, ecology and sustainability are all concepts challenging today's' industry, especially the luxury market. This paper investigates the WTP for luxury electric vehicles and their attributes within the favorite brand. We therefore highlight the ecology effect on Decision making (loyalty vs. churning). The results show high preferences for ecology (reduction of Co2 emission) as well as a high loyalty level. Unlike previous investigations, we found out that prosperous clients are not accepting lower ranges and longer charging times, even if they possess multiple vehicles. Moreover, they are willing to pay up to $10 \%$ more for environmental friendly cars from favorite brand (assumption: quality doesn't succumb status-quo). Serving these clients with the right product, allow luxury car manufacturers to charge significantly higher prices and therefore to increase profit and market share. Ignoring Ecology in the luxury car market results in customers' churn.

\section{Introduction}

Sustainable and environmental friendly goods are daily gaining importance and responsiveness. This has pushed companies to acclimate their strategies into "green" policy. Even luxury manufacturers are concerned since this can wholly destroy the business and lead to customer churning. The risk is particularly high in this segment due to its sensitivity and to the intricate customer requirements. For instance, researchers like Bendell and Kleanthous, Kapferer and, Kapferer and Michaut [1-3] discussed the implications of ignoring these norms, even if clients do not acclaim them openly. Unlike regular merchandises, prosperous buyers have a deep liaison to their favorite brands due to the social, individual and functional benefits offered by luxury products [4-7]. This 'loyalty' suggests a forgiveness buffer when these companies partially lose their appeal or are temporary inferior relative to the competition. In other words, people are more likely to disregard some attributes to, further consume their desirable trademarks. For example, one would ignore a missing Navigation system in a Ferrari, but not in a Volkswagen. However, many uncertainties should be revealed: to which extent customers would forgive their favorable brands when ignoring some aspects such as sustainability and ecology? What are the car attributes that enhance the WTP and therefore loyalty?
This work evaluates the key aspects and motivations for luxury electric car buyers. In addition, it models the tolerance level for manufacturers. Many arguments legitimize the choice of the automobile segment. First, the market share within luxuries is about 40\% (€489 billion out of €1,2 trillion) in 2017 and shows a continuous growth of $8 \%$ compared to 2016 (Bain and company, 2017). Second, due to a low purchase frequency and to a high investment rate, people are more rational in their decisions. In addition, unlike fashion or jewelry, there is no discrimination effect since both genders appreciate cars and use them. Fourth, a car symbolizes the best way to project prosperity such as Status and prestige because they can only be consumed publicly. Finally, product experience (previous/ current) with a vehicle have generally a long cycle and shapes therefore the foundation for future choices [8,9]. For example, for someone who likes a specific car and had a pleasing experience with it, the next purchase is more likely to occur within the same brand. Even if the acquired product is the poorest in their evoked sets, it is expected that clients would ignore some features and needs toward savor the brand. Typically, this is what all brands implicitly strive for because it strengthens the true brand value through a forgiveness level. 


\section{The Effect of Brand and Customer Specificities on Loyalty}

The academic literature on brand experience [10], brand attitude [11], brand involvement [12], brand attachment [13], brand personality [14] and brand image [15], Martínez Salinas \& Pina Pérez, [16] studied the impact of firms' dimensions on consumers' loyalty in different ways. They acknowledged these assets as key aspects for a firm's success. Furthermore, Aaker [17] and Grohmann [18] empathized the importance of self-congruence in affecting customer response to the brand. Generally, shoppers seek products that better symbolize them with particular traits to express their self-concept. Thomson et al. define it "as the cognitive and affective understanding of who and what we are." Besides, the concept contains two different facets: the 'actual-self' (based on perceived reality of the self) and the ideal-self (based on dreams, goals and the striking self). According to Aaker [17] both ways can lead to self-congruence through a brand that match one of the two traits. Once people find the variety that fulfil this necessity, they become more attached to it and, therefore loyal. However, most of the theories mentioned above flow in one direction (B2C). Consequently, it is necessary to reveal the darkness on consumer's ability, involvement and motivation to process information, and his/her perception of the brand. Duesenberry [19] was the first to introduce the idea of "habit formation" where he showed that current behavior is partially affected by past consumptions. This was affirmed by Pollak [20]. Similarly, Lancaster [21] pointed out that people consume a specific product because of its inherent values and surplus. Hawkins and Hoch [22] for example, observed subjects' judgement under different involvement levels. The findings suggest that familiarity is a mediator for the truth effect. Meaning, when exposed to a familiar product, a so-called "ring the bell" reaction occurs and people are more likely to trust the information. Consequently, luxury car producers should make use of this finding (familiarity \& market share) to introduce sustainable and environmental friendly goods. In the same context, Malär, Krohmer, Hoyer and Nyffenegger [23] presented a conceptual framework that illustrates the relationship between self-congruence and emotional brand attachment. The model announces self-esteem, public self-consciousness and product involvement as mediators. In other words, customer' characteristics and his/her involvement determine his/her relation to the brand. They are more related to the brands that better reflect and confirm who they are rather than to those that promise helping them achieving the ideal-self. Highend manufacturers are then expected to identify new tendencies such as ecology and apply the right strategies to serve the new clientele. Such approach is decisive for both loyalty and future success. Nonetheless, loyalty is a relative concept since clients are always seeking to maximize their utility (material \& immaterial) through acquisition or consumption [24-26]. They might turn the wheel and choose completely different goods that better fit their current needs. In general, people think they make decisions based on trivial traits such as product attributes and monetary values. In fact, a real complex computation is behind. They, unconsciously, develop an approach based on both product related experience (emotional outcome from previous purchases) and expertise (ability to perform product related tasks successfully) to facilitate the decision-making process.

To help marketers with "a useful foundation for research on consumer behavior", Alba and Hutchinson [27] introduced five dimensions of consumer expertise (cognitive effort, cognitive structure, analysis, elaboration and memory). The first two dimensions mentioned above were shown to have a positive benefit on the latter. The Authors identified a simple but a potent effect of repetition on cognitive effort: Familiarity reduces both the effort and the reaction time during decision-making (automaticity). The second dimension describes the weights of the facts for both novices and experts. For instance, this cognitive structure correlate positively with familiarity. Practitioners should be aware of this finding that mediates the loyalty philosophy and make use of it. For instance, in case market leaders are up to date, customers would trust them more than others and their decision won't include a complex computation (automaticity). Pham and Johar [28] confirmed this finding and proposed a model of source identification. They described the hierarchical source monitoring when people fail to retrieve the information's source. The results seem to be trivial and useless for practitioners, but it is crucial in reality. For instance, the usage of unique labels, features, logos and tools permits to associate the brand with a higher individuality degree. Therefore, the retrieving procedure follows the easiest and shortest path within the suggested model. In other words, people are familiar with the brand and are more likely to prefer it among all others. If people decide to leave their favorite brand, an alarm should be triggered.

In another work, Maclnnis and Jaworski [29] studied the information processing from advertisements. The proposed integrative attitude formation model differentiates between utilitarian and hedonic needs, which result in cognitive and emotional responses. Furthermore, it stresses the effect of clients' AMO (ability, motivation and opportunity to process brand information). Likewise, the outcome is useful in practice. For example, the model can be divided into 3 main blocks (AMO, elements of brand processing and the evaluative level) which makes it useful as a diagnostic tool. In this case, it is easy for firms to locate the deficit, if the choices and attitudes are inconsistent with the input (needs and AMO-antecedents). All the suggested studies empathized the importance of consumers' ability, motivation and opportunity to process the brand information on their attitudes toward a company (loyalty). Understanding buyers' preferences in general and the consistency of the brand perception with the firm's expectations specifically is advantageous. Therefore, marketing researchers and practitioners need the complete set of puzzles to derive a consistent judgment, since fitting this discrepancy permits to achieve an additional powerful dimension.

\section{Customer Churning}

The churn philosophy can be classified into voluntary and nonvoluntary. The non-voluntary churners are easy to identify and to deal with [30]. These are customers who are pushed to abandon 
the brand for several explanations. For example, when firms revoke a package or when clients are unable to pay an arrangement. it is more critical when it emanates to voluntary churn. People make then a conscious decision to cut with the brand. Afterwards, they switch to competitors. Analogous, this can be decomposed into two categories: incidental and deliberate churn. The former happens when specific conditions avert the customer from his current consumption For instance, if he can't afford the required financial means or moves to an unsuitable - geographical- area. The user is then more likely to terminate his rapport to the brand. The latter reveals high challenges for most companies. It occurs when the clientele starts to empathize competitors' products due to their superiority in terms of technology, quality and economical attributes. In this case, the task becomes tough through both, the intense competition and the variety of products and services that faces the customer. Thus, Liu and Shih [31] related to the indispensability of new strategies that capture customer needs, progress the satisfaction level and so, retention. It has become a commonly acquaintance that company's' most importantasset is the customer [32-33] Subsequently, businesses are opting customeroriented strategies for sustaining their competitiveness and guarantee a stable profit. However, Keaveney (1995) accentuated the difficulty and the costs (advertising, promotional expenses etc.) of such processes in a saturated market where customers constantly face a gigantic variety of products and services. To this issue, Burez and Van den Poel [34] identified two approaches: the reactive and the proactive. Firms that adopt the reactive way are more passive. They wait until clients ask to cut the relationship. At that point, they offer the customers higher incentives to hold them. Even if they succeed preserving their clients, the drawbacks like excessive costs, lower brand mercy and, purely incentive oriented relationship will overwhelm. Contrarily, the proactive procedure occurs when businesses primary focus on identifying risky clients (that are more likely to churn) and try to retain them. This kind of targeted strategy is advantageous. It allows to protect the core business and to save market share. Additionally, proactive firms are generally more innovative and so, have a better image. Nonetheless, Van den Poel and Larivie're [35] stressed the disadvantages of an inaccurate procedure. For example, companies would offer high incentives to clients who are not really churning.

Therefore, it is essential to be up to date, to identify the new tendencies, and to offer the clienteles the product and the quality they are looking for (or maybe a touch above). Moreover, it is recommended that companies aim new customer generation [3638]. Traditional methods of predicting churn risk are unprecise since they only identify trends in data using pure mathematical algorithms. Additionally, businesses are often unable to identify if a customer is more likely to switch to competitors until it is too late. The main reason for the usage such soft computing algorithms, is their low cost. For the prediction of churn risks, companies used to apply a pure demographic-based model. Wei and Chiu [39] criticized this approach since it creates an analysis which is based on customers and ignore all other facets such as product attributes. Furthermore, due to restricted customer information, a pure demographic-based-prediction won't be efficient. Additionally, the luxury academic literature on brand associations (attachment, love, involvement etc.) ignore such facets. They assume a continuous relationship (untainted loyalty) once the customer appreciates a brand.

\section{Empirical Study}

\section{The bayesian tradition: definition and properties}

Powerful tools for estimating discrete choice models have been settled within the Bayesian technique. Unlike traditional processes, these new methods can estimate model parameters without calculating the choice probabilities. Furthermore, they are efficient in deriving parameters on the individual level within any model and under random taste variation. For example, Albert and Chib [40] have developed an exact Bayesian approach for modeling categorical response data using the idea of data argumentation. McCulloch and Rossi [41] established new methods for conducting a finite sample, likelihood-based analysis of probit. The algorithm uses a variation of the Gibbs sampler and avoids a direct evaluation of the likelihood. Bayesian methods have numerous advantages compared to frequentist. First, unlike probit and mixed logit where the MLE (Maximum Likelihood Estimator) can be associated with numerical difficulties, Bayesian doesn't require any maximization. Furthermore, traditional algorithms fail to converge in such situations and doesn't guarantee that the maximum has been reached. Even the choice of the starting values is still an issue Train, [26]. Second, Bayesian procedures guarantee consistency and efficiency with more relaxed assumptions. For instance, its estimators are consistent for a fixed number of draws. If this amount rises at any rate with sample size, the coefficients are efficient. Cameron and Trivedi [42] stated out that Bayesian procedures guarantee higher flexibility for the researcher since they deliver the entire posterior distribution of the parameters of interest. Meaning the user can decide which moment/ quantile of the distribution to report based on decision theoretic criteria. Unlike frequentists, Bayesian methods are conditioned on data. The results are exact finite and approach the normal distribution in large samples where the influence of priors disappears. Finally, Bayesian provides a natural way to select models $[42,26]$.

However, the Bayesian approach is linked to some costs especially for researchers who are used to classical ways. They need to be more familiar with various interrelated techniques. Afterwards, the learning curve gets steep. Also, the convergence is an issue, since Bayesian models use enough iterations to converge (takes a long time too). Unlike the convergence to a maximum by traditionalists. Bayesian scientists cannot therefore easily determine whether it is achieved or not. According to Train [26], McCulloch and Rossi [41] and, Albert and Chib [40], Bayesian are in many cases faster than classical approaches and provide satisfying pattern for inference and decision making. Under certain assumptions, the estimators are asymptotically equivalent to the MLE and can therefore be interpreted in a classical way. The researcher has initially some ideas about the parameters $\theta$ of his/her model. He/she collected data to improve or to update 
his/her beliefs that are represented by a probability distribution $(\mathrm{P}(\theta))$ over all possible values that $\theta$ can take. This is termed prior. $\mathrm{He} / \mathrm{she}$ observes the choice of $\mathrm{N}$ independent decision makers $Y=\left\{Y_{-} \_1, Y_{-} 2, \ldots Y \_N\right\}$. Based on this sample information, the scientist updates his/her ideas about the value of $\theta$. This is denoted as posterior distribution $\mathrm{P}(\theta \mid \mathrm{Y})$ and depends on y since it only incorporates the information contained in the observed sample. In conclusion, there is a definite relationship between the posterior and the prior through the Bayes' rule:

$$
\mathrm{P}(\theta \mid Y)=\frac{\mathrm{P}(\theta \mid Y) \mathrm{P}(\theta)}{\mathrm{P}(Y)}
$$

with $\{\mathrm{P}(\theta \mid Y)$ is the likelihood

$\left\{\mathrm{P}(Y)\right.$ is the marginal likelihood/evidence $/ \mathrm{P}(Y)=\int \mathrm{P}(\theta \mid Y) \cdot \mathrm{P}(\theta) d \theta$

\section{Specification of the prior}

The researcher can choose between non- and informative priors depending on the available data and his/her goal. Noninformative priors have minor impact on posteriors. It is an effortless way since the choice of a uniform prior $\pi(\theta)=c(\forall \theta /$ $c>0$ ) places equal weights on all possible values of $\theta$. However, in cases where the parameters $\theta$ are unbounded, the density $\int \pi(\theta)$ $d \theta=\infty$ is improper and implies an improper posterior. Also, the prior is invariant to reparameterization. Meaning, if it is unsuitable for one parametrization, it will be unsuitable to all others. A wellknown uninformative prior is the Jefferys' prior (Also known as vague, diffuse or flat) which has a large variance $\sigma^{2}$. It can serve as a method of generating a prior when there are no obvious candidate priors available. Conjugate priors (informative or diffuse) require a convenient functional formula for the prior and result in a good and methodically tractable illustration of the posterior under definite sample density of the data. Natural conjugate pair means that the sample density, prior and posterior, lie in the same class of densities (Figure 2). Table 1 summarizes the most used conjugate families (Figure 1\&2) (Table 1).

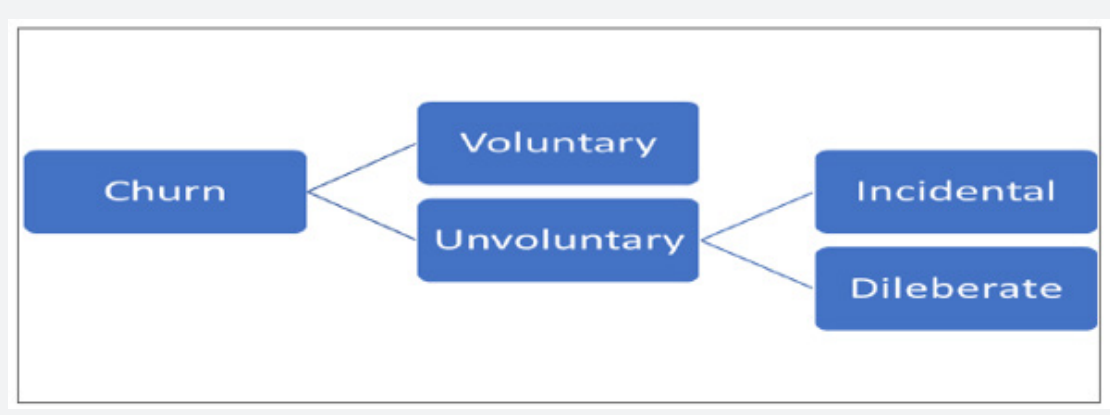

Figure 1: Different churning types.

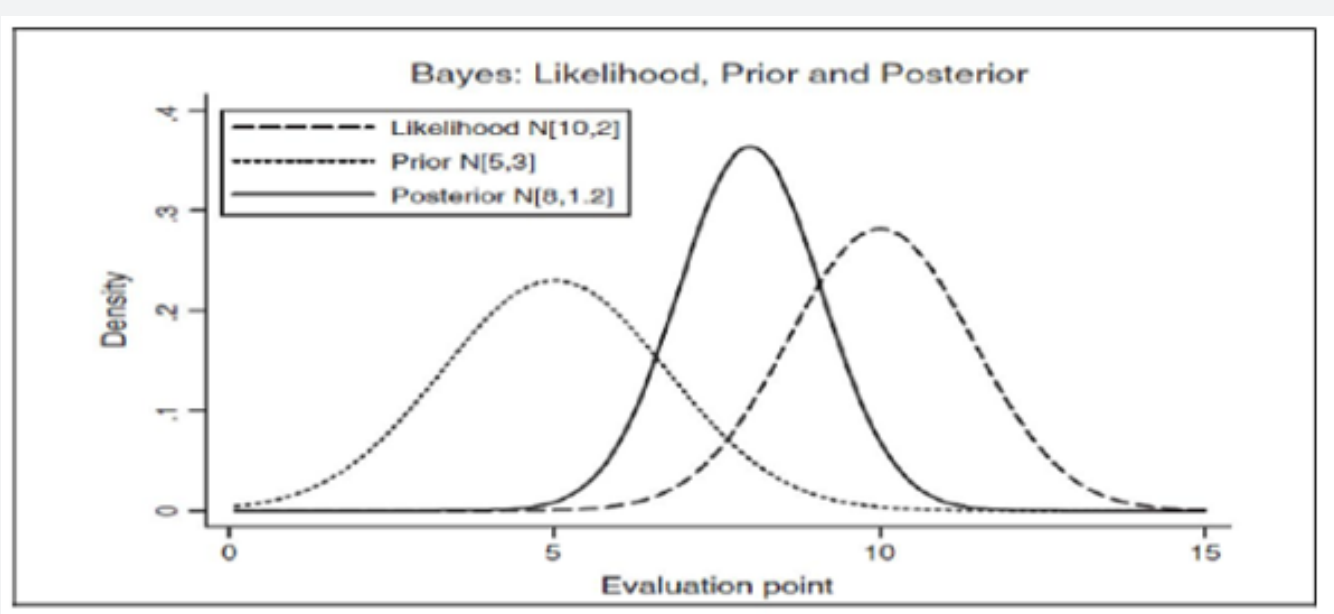

Figure 2: Bayesian analysis of mean parameter of normal density.

Table 1: Most used conjugate families.

\begin{tabular}{|c|c|c|}
\hline Distribution & Sample density & Conjugate prior density \\
\hline Normal & $N\left[\theta, \sigma^{2}\right]$ & $\Theta \sim N\left[\mu, \sigma^{2}\right]$ \\
\hline Normal & $N\left[\theta, 1 / \theta^{2}\right]$ & $\Theta \sim$ Gamma $[\alpha, \beta]$ \\
\hline Binomial & $\beta[N, \theta]$ & $\Theta \sim$ Beta $[\alpha, \beta]$ \\
\hline Poisson & $\mathrm{P}[\theta]$ & $\Theta \sim$ Gamma $[\alpha, \beta]$ \\
\hline
\end{tabular}




\begin{tabular}{|c|c|c|}
\hline Gamma & $\operatorname{Gamma}[v, \theta]$ & $\Theta \sim$ Gamma $[\alpha, \beta]$ \\
\hline Multinomial & $M N\left[\theta_{1}, \theta_{2}, \ldots, \theta_{k}\right]$ & $\theta_{1}, \theta_{2}, \ldots, \theta_{k} \sim$ Drichelet $\left[\alpha_{1}, \alpha_{2}, \ldots, \alpha_{k}\right]$ \\
\hline
\end{tabular}

\section{Markov chain monte carlo simulation}

The researcher aims to get a large sample from the posterior distribution since it provides desired information about both the moment characteristics of the sample of estimates and other relevant measures. This task is more complicated if there is no closed-form expression for posterior density. Using Monte Carlo Markov Chain method, the scientist run sequential draws that harvest simulated values. Running long enough sequences is a key aspect here. Subsequently, the values converge to a stationary distribution that coincides with the target posterior density $\mathrm{p}(\theta \mid \mathrm{Y})$. the Method named MCMC referring to simulation Monte Carlo and the sequence of Markov Chain that uses 2 approaches: Gibbs Sampler and Metropolis Hastings. In conclusion, product characteristics have a key influence on decision making. On the one side, product involvement/ characteristics and brand relationship build the fundament of the behavioral aspects especially, in the highend segment where people are better informed, experienced and have deeper liaison to their favorite manufacturers. On the other side, as mentioned by the economic perspective, customers seek to maximize their relative utility through the choice of a specific good among others. A juncture of both views yields the decision either to buy or not and which product. Again, this is primary for luxury houses since psychological, social, functional and financial dimensions play a deeper role in the decision making compared to mass producers.

\section{Choice of attributes and data collection}

As mentioned above, the car industry is a main component for the success and the accomplishment of the luxury market. For instance, an increase of round $11 \%$ was recorded between 2016 and 2017 so that the business' market share is about $41 \%$ (€489 billion out of €1,2 trillion) in 2017 Bain and company, [43]. Additionally, the appearance of new tastes, namely ecology and sustainability has led to numerous challenges. Car manufacturers have the task to, first conserve their clients who are looking for the fundamentals of high-end merchandises, and second serve the new tastes and attract them. Numerous studies $[44,45])$ have been conducted to elucidate the willingness to pay for electric vehicles. Based on the following car attributes: driving range, charging time, fuel cost saving, pollution reduction, and performance, respondents were asked to choose between three alternatives, the vehicle they are more likely to buy. as a result, people prefer functional features like higher driving range, fuel cost saving and faster charging time. The $\mathrm{Co}_{2}$ emission, which is the specificity of battery electric vehicles (BEV), was significant but not conclusive in the decision making. All studies were aiming to evaluate car attributes and were about mass products. However, prosperous buyers have a unique impulse and their relations to brands are much more robust. Subsequently, their choices and preferences are based on completely distinct aspects that should be investigated. Thus, luxury car producers obtain a better and wider view on the new market necessities. Unlike commodities, high-end products should display status and some other social ans individual values through high quality, exclusivity, indulgence etc. $[4,46,6,47,48]$. Most prosperous buyers are therefore seeking expensive goods that keep them privileged or at least guarantee a certain status level. Performance in terms of acceleration is an excellent quality and prestige indicator. Fast vehicles are gladly seen and appreciated. Subsequently, the owner not only enjoys the driving experience, he/she also adores being honored and appreciated by others since cars can only be consumed publicly.

- H1a: independent on their backgrounds (e.g. snobs, Veblenian etc.), all prosperous buyers show strong preferences for high acceleration from favorite car manufacturers.

The arousal theory builds the fundamental of the behavioral psychology in understanding decision-makings. Besides, while this work deals with the WTP for luxury EVs, it is necessary to reveal the darkness on some aspects like customer need for novelty and his/ her perception of new products like ecological luxury vehicles. According to academics like Garcia- Torres [49]and JohnsonLaird, Girotto and Legrenzi (2004) [50], and Legrenzi and Umita [51], the arousal level is positive and, strongly related to wellbeing and feelings. Subsequently, it determines peoples' performances. Furthermore, the theory supports the idea that performance necessitates a variety of stimuli (Hebb [52]; Berlyne, 1970 [53]). For instance, clients prefer a rich set of products with distinctive features, so they have enough choice and their decision would be more consistent. However, the authors recommend a moderate arousal level since its' consequences follow a U- inverted curve: very low as well as very high stimulations won't allow people to perform well. Likewise, this finding is primary for luxury car manufacturers since producing non-familiar vehicles might have negative consequences.

Berlyne [53,54] investigated the novelty effect on buying decision. He stated out that customer' need for newness and originality affects the hedonistic degree of the stimuli. Meaning, people favor to get enough stimuli from outside to be well. This overlaps with the fundaments of luxury such as high quality, exclusivity and other hedonic values. Nonetheless, he argued that familiarity correlates negatively with the arousal level. As an illustration, when customers are repeatedly exposed to the same product (-set), their appreciation and excitement decreases (Nelson \& Meyvis [55]. Therefore, choosing a convenient time and strategy in presenting their products is a challenge for luxury companies. Likewise, selecting which features and attributes a product should have is decisive. Moreover, the diversity of prosperous buyers, their needs, motivations and wishes makes the task more complex for manufacturers. For instance, car producers should simultaneously 
serve different tastes like environmental friendly clients with electric/Hybrid vehicles, and people who seek the fundaments of luxury with extravagant and exclusive cars. To summarize, unlike the rational view, the arousal theory assumes that customers don't know what they want specifically. But they are trying to maintain their arousal level constant through the seek for newness (GarciaTorres [49]). This postures a challenge for luxury car manufacturers while introducing electric cars. Additionally, the luxury literature underlies the role of price as a quality indicator for all customer categories (snob, Veblenian, Bandwagon \& perfectionist). There exists a lower bound under which none of them would buy the good because it is a harmful quality signal. Above this amount, the diverse groups are formed depending on their individual, social and functional needs, and readiness to pay (Vigneron \& Johnson, 1999 [56]). Unlike the mass market, where the decision to acquire alternative fuel vehicles correlates positively with cost-savings (e.g. fuel \& maintenance) Jansson [57], prosperous clientele is seeking expensive goods with exceptional experiential aspects such as sportiness.

H1b: prosperous buyers are willing to pay higher prices for performed luxury EVs from favorite luxury car manufacturer.

The charging time and the range are functional attributes that are decisive in the DM. In the mass market Hidrue et al. [44] found a negative effect of coming from a multicar household on the willingness to buy electric vehicles. Similarly, and unlike what most people would think (Flexibility: Prosperous buyers have access to many cars. Therefore, they can switch between them depending on their needs), we reason that the same effect is present in the highend segment. This clientele is experienced, seeks the fundaments of luxuries and, have therefore higher standards and wishes. Independently, if they have 20 or 30 Hermès handbags in the wardrobe, the new one should not be minor to their possessions on any dimension (functional, social, individual and financial). Besides, it should be better at least in one fact. Similarly, someone who owns a Ferrari, a Porsche and a Lamborghini is less likely to buy a new vehicle that has lower acceleration, range, etc. than his statusquo. This idea is also supported by various theories on innovation adoption where people are willing to buy the new product only if it shows better features (Jannsson, [57]. This is also consistent with the luxury literature $[4,46,6,47,48]$ ) which highlights quality aspects as a corner stone in the market.

- H2: improved functional aspects such as better range and shorter charging time correlate positively with the WTP for luxury EVs from preferred luxury brand.

Also, the marketing of innovative products such as alternative fuel vehicles is always linked with subsidiaries (non- and monetary). Both government and companies encourage this in several ways like unrestricted parking, tax- exemption and free charging. These attributes are important for this study to find out how they affect the buying decision and how they correlate with the number of cars in household as a mediator. Studies on the willingness to buy electric cars in the mass market Hidrue et al. [44] showed the importance of reducing battery costs and of introducing non- and monetary subsidies on DM. This is understandable since these monetary advantages, evidently influence the utility function. Outgoing from luxury literature on buying motivations [56,58], on product definition and associations $[46,48,59]$, financial and social motives like status and recognition are major buying motivations. For instance, there is a positive correlation between price and quality in the segment. Expensiveness implies superior quality. Therefore, we expect a minor effect of subsidies on the wtp for luxury EVs since this might be a bad quality signal.

\section{- H3: The introduction of non- and monetary subsidies such as tax exemption has little to no influence on the WTP for luxury EVs.}

The $\mathrm{Co}_{2}$ emission is key aspect and a specification of BEVs. Therefore, it is essential to study its' impact on the buying decision. According to the behavioral decision-making theories (chap. 3), customer ability to process information and his involvement have key effect on his decision. Studying his/her willingness to pay for EVs vis-à-vis his/her engagement and appreciation for ecology, gives a wide view on the choice and helps marketers to better understand the key motivations for ethics in luxury. It is therefore a combination of behavioral and economic perspectives to derive an appropriate estimation. Moreover, this allows to clarify the conflict within the luxury literature: On the other side, Ward and Chiari, Davies et al. $[60,61]$ for example, sympathize sustainability as an exceptional and trendy marketing tactic, but don't consider it decisive like the fundamentals of luxuries. For instance, they cited many arguments like the low-buying-frequency. People buy once a week fair traded coffee bones and feel then helping others through this conscious behavior. However, they don't buy a Rolex or a Ferrari in the same tact. Additionally, the researchers proclaim the availability of environmental friendly goods as well as their quality as a feebleness. Finally, they argue that the purchase act is an intimate moment where only enjoyment and self-reward are major factors. On the one side, researchers like Bendell and Kleanthous, Kendall, Bendell, Wiedmann et al. and Kapferer [1,3,7,62,63] underlies ecology as key aspect in the segment. Furthermore, they warn from ignoring it, even if customers don't acclaim it openly. The authors showed that the appearance of new ecological luxury consumers like the LOHAS as well as the increasing demand for green products (from traditional buyers) makes ecology decisive in the market. Nonetheless, a comparison between luxury fundaments with the ecology principles showed numerous intersections. As an illustration, the fact that we should fairly handle with rare resources implies a limited production that is also costly. As a result, we get exclusive products that have a good quality but also expensive which overlaps with luxury values. Besides, luxury start-ups like Tesla, Elivs \&Kresse or Schilpachavan combine creativity, environmental friendliness with high-tech to get advantages and compete with market leaders. This pressure is continuously pushing established firms to introduce similar concepts. As an illustration, luxury car manufacturers started immediately the production of EVs whereas the rest announced upcoming models with better features. 
- H4: Prosperous buyers have high preference for $\mathrm{Co}_{2}$ emission reduction.

For this purpose, 243 luxury customers participated in the study (147 male and 97 female). Only respondents who were planning to buy a luxury car in the next 7-9 months were kept to get more realistic choices. At the beginning, they completed a set of questions on the luxury car they are more likely to purchase (from favorite brand). Moreover, the survey includes measures of environmental friendliness and on materialism settled by Haws, Winterich and Naylor, and Eastman, Goldsmith and Flynn $[64,65]$ respectively. The "green scale" contains 6 questions that are evaluated on a 7-points Likert scale. The sum serves as an ecology indicator. In the same way, the materialism level is defined through a reliable and valid question catalog. The collected data includes demographic information that are relevant to study the willingness to pay for luxury electric vehicles. In addition to the standard data like age, income and gender, the number of cars in household, the education level and the budget dedicated to the next purchase were collected (Figure 4). Also, the education level is a good indicator for ecology, as well-educated people are more aware about environmental issues and are therefore more likely to adapt their behavior. The goal here is to find out if the ecology level is the main factor influencing the buying decision. Meaning if prosperous consumers acquire EVs predominantly because of the low $\mathrm{Co}_{2}$ emission or more due to values like (exclusivity, enjoyment, etc.) provided by luxury products. The number of cars serves then as a moderator since multicar households are supposed to be suppler. For example, they might use another vehicle if the charging takes too long or when the trip clearly exceeds the battery capacity. Finally, people gave the amount they are dedicating for the car purchase. Combined with the output of the conjoint analysis the researcher can identify the consistency of the decision and which attributes (levels) are key aspects here. This is essential to model the choice and to identify both churners and the churn causes within a luxury brand (Figure 3,4).

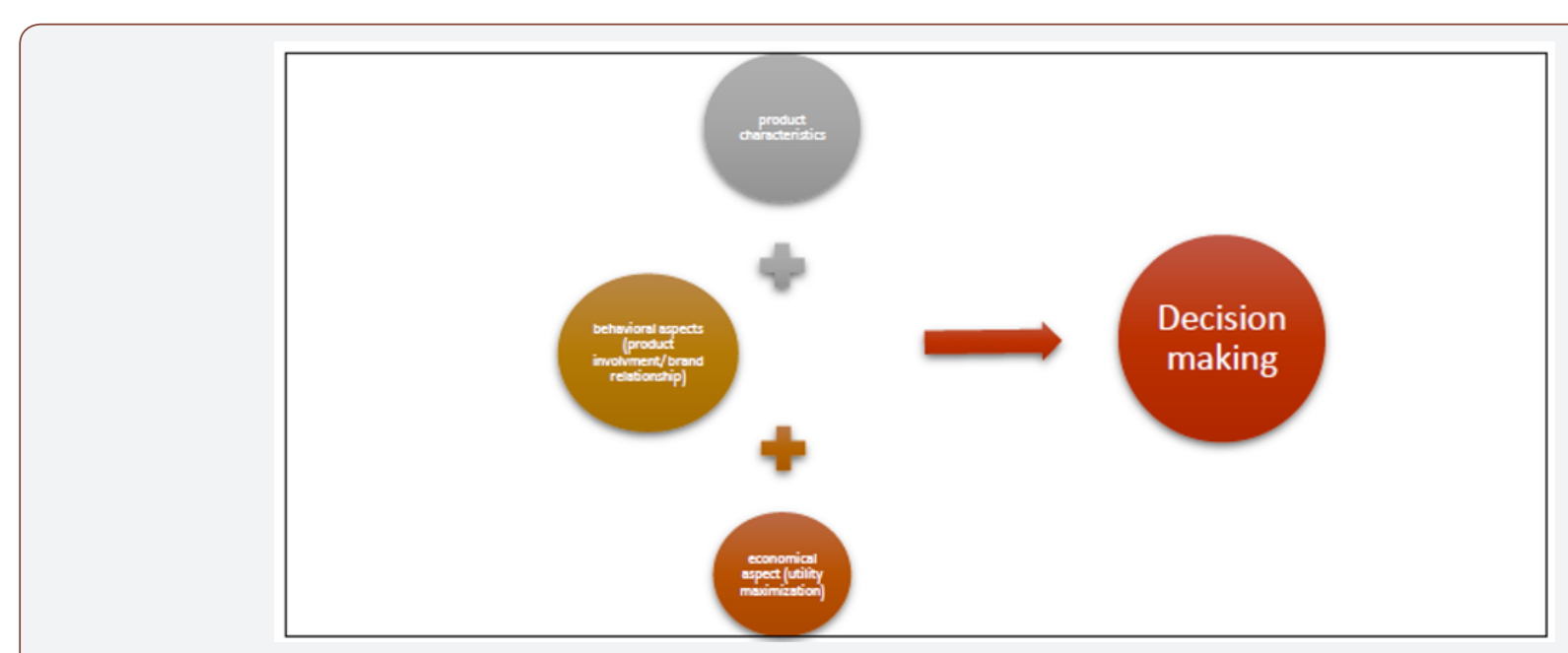

Figure 3: Decision making Procedure.

\begin{tabular}{|c|c|c|c|c|c|c|c|c|}
\hline \multirow{2}{*}{$\begin{array}{l}\text { Cars. in. householo } \\
\text { Min. : } 1.000\end{array}$} & d Environment & \multicolumn{2}{|c|}{ Gender } & Conspicuous & wage & Age & Budget & Profession \\
\hline & Min. & Min. & $: 1.000$ & $: 5.0$ & $: 1.000$ & Min. $: 18.00$ & $: 1.000$ & $: 1.000$ \\
\hline 1st Qu.:2.000 & 1st Qu. :25.00 & 1st Qu. & 1.000 & 1st Qu.:12.0 & 1st Qu.:2.000 & 1st Qu. :25.00 & 1st Qu. :2.000 & 1st Qu. : 3.000 \\
\hline Median :3.000 & Median : 30.00 & Median & : 1.000 & Median :18.0 & Median :4.000 & Median :30.00 & Median :4.000 & Median : 4.000 \\
\hline Mean :3.037 & Mean $: 28.84$ & Mean & :1.395 & Mean $: 18.4$ & $: 3.683$ & Mean :33.81 & Mean :3.621 & $: 3.905$ \\
\hline 3rd Qu. : 4.000 & 3rd Qu. : 35.00 & 3rd Qu. & $: 2.000$ & 3rd Qu.:25.0 & 3rd Qu.:5.000 & 3rd Qu.: 42.00 & 3rd Qu.: 5.000 & 3rd Qu. : 4.000 \\
\hline Max. $\quad: 5.000$ & Max. $\quad: 42.00$ & Max. & $: 2.000$ & $: 35.0$ & $: 7.000$ & $: 69.00$ & $: 7.000$ & $: 8.000$ \\
\hline Education & facwage & faccars & & & facedu & & & \\
\hline Min. $\quad: 1.000$ & No income: 32 & 1 car :18 & vocat & ional baccalaur & ate diploma: 15 & & & \\
\hline 1st Qu.: 6.000 & $<36 \mathrm{~T}$ & 2 cars:71 & GCE & & $: 5$ & & & \\
\hline Median :7.000 & $37-50 \mathrm{~T} \quad: 14$ & 3 cars:72 & vocat & ional technical & diplona & & & \\
\hline Mean :6.506 & $51-75 T \quad: 13$ & 4 cars:48 & comp. & apprenticeship & $: 8$ & & & \\
\hline 3rd Qu. :7.000 & $76-126 \mathrm{~T} \quad: 64$ & 5 cars:34 & highe & degree & : & & & \\
\hline Max. $\quad: 8.000$ & $127-250 \mathrm{~T}: 41$ & & GCSE & & : & & & \\
\hline & $>250 \mathrm{~T}$ & & (othe & & $: 2$ & & & \\
\hline
\end{tabular}

Figure 4: Summary of demographics.

The respondents were given three models of their favorite car, which they are willing to buy closely: a BEV, a PHEV and an ICE. For the ICE cars, only price and performance were varying to study the hedonism effect in the decision-making: Buying (or not) EVs due sustainability or to luxury values such as trendiness and high acceleration. The questionnaire doesn't mention concrete manufacturers since each respondent has a different favorite car and his loyalty and brand relationship (involvement, love, attachment, etc.) is relative. For instance, both Ferrari and Porsche owners love their cars and enjoy their experiences, but they have different relations due to diverse brand facets. Furthermore, a none- choiceoption is added to allow for churn prediction. When preferred 
manufacturers ignore ecology and sustainability, churners are then more likely to purchase other goods from their evoked set. In other words, they, voluntary, switch to a competitor that affords them the functional, individual and social values they are looking for. Each respondent was shown 17 choice cases and should pick up the alternative he is more likely to purchase. The attribute variation was in percentage and relative to the basis version of that model since every participant has a different preferred car. Thus, the result is more realistic and generalizable which implies consistency. Based on collected data from diverse manufacturers (Table 2), it becomes clear which attribute levels are more realistic for the analysis. All models within a category have similar characteristics. For instance, the average range is around $550 \mathrm{~km} \mathrm{(+-} \mathrm{10 \% )} \mathrm{which}$ match with a combustion car. This is also the case of PHEV when adding the electric range to the regular one. Moreover, numerous manufacturers have special charging stations where around $80 \%$ of battery capacity is reached in less than $30 \mathrm{~min}$. However, people have the domicile charging option which obviously has lower efficacy. Integrating this option in the conjoint analysis is indispensable since people feel more comfortable charging their cars at home. Also, the reachability and the geographical distribution of charging stations is still an issue especially in villages. Contrasting the theories of disruptive innovations $[66,67]$ that undertake the idea of lower price and inferior quality for the new good, luxury EVs are faster and more expensive than numerous luxury vehicles. For example, the Tesla Model S P100D costs around €157.670 and goes from 0 to $100 \mathrm{Km} / \mathrm{h}$ in 2,7 seconds (Table 2). A Mercedes S560 4Matic has a price of $€ 116,994$ and a speeding up of 4,6 seconds from 0 to 100 $\mathrm{km} / \mathrm{h}$ (Mercedes- Benz, 2017) (Table 2).

Table 2: Conventional premium-luxury ICEs EVs and PHEVs.

\begin{tabular}{|c|c|c|c|c|c|c|c|}
\hline $\begin{array}{l}\text { Manufacturer } \\
\text { (Model) }\end{array}$ & Price $[€]$ & Energy & $\begin{array}{c}\text { E-Range } \\
{[\mathrm{km}]}\end{array}$ & Charging time in min & $\stackrel{0-}{100 \mathrm{~km} / \mathrm{h}}[\mathrm{sec}]$ & $\begin{array}{c}\mathrm{CO}_{2} \\
{[\mathrm{~g} / \mathrm{km}]}\end{array}$ & Source \\
\hline $\begin{array}{l}\text { Tesla Model } \\
\text { S 85D }\end{array}$ & 92.8 & $\mathrm{BEV}$ & 528 & $\begin{array}{c}\text { Supercharger: } 270 \mathrm{~km} \\
\text { in } 30 \mathrm{~min} \text {; Wall connector: } 100 \mathrm{~km} / \mathrm{h}\end{array}$ & 4,4 & 0 & Tesla, 2015 \\
\hline $\begin{array}{l}\text { Tesla Model } \\
\text { S P100D }\end{array}$ & 157.67 & BEV & 613 & $\begin{array}{l}\text { Supercharger: } 270 \mathrm{~km} \text { in } 30 \\
\text { min Wall connector: } 54 \mathrm{~km} / \mathrm{h} \text { or } \\
81 \mathrm{~km} / \mathrm{h}\end{array}$ & 2,7 & 0 & Tesla, 2017 \\
\hline $\begin{array}{c}\text { Tesla Model } \\
\text { X }\end{array}$ & 166,150 & $\mathrm{BEV}$ & 542 & $\begin{array}{c}\text { Supercharger: } 270 \mathrm{~km} \text { in } 30 \mathrm{~min} \\
\text { Wall connector: } 54 \mathrm{~km} / \mathrm{h} \text { or } 81 \mathrm{~km} / \mathrm{h}\end{array}$ & 3,1 & 0 & $\begin{array}{l}\text { Tesla, } \\
2017 a\end{array}$ \\
\hline Artega Scalo & $170.000-$ & BEV & 400 & Fast Charger: <1h; Haushalt: $10 \mathrm{~h}$ & 3,6 & 0 & $\begin{array}{l}\text { Artega, } \\
2015 a\end{array}$ \\
\hline BMW i8 & 130 & $\begin{array}{c}\text { PHE } \\
\text { V }\end{array}$ & 37 & $\begin{array}{c}\text { 2,5h; } \\
\text { Wallbox: } 2 \mathrm{~h}(80 \%)\end{array}$ & 4,4 & 49 & $\begin{array}{l}\text { BMW, } \\
2015 a\end{array}$ \\
\hline $\begin{array}{l}\text { Porsche } \\
\text { Panamera S } \\
\text { E-Hybrid }\end{array}$ & 106.72 & $\begin{array}{l}\text { PHE } \\
\text { V }\end{array}$ & 36 & $\begin{array}{l}80 \%: 15 \mathrm{~min} \\
100 \%: 2,3 \mathrm{~h}\end{array}$ & 5,5 & 71 & $\begin{array}{l}\text { Porsche, 2015b; } \\
\text { Porsche, 2015a }\end{array}$ \\
\hline $\begin{array}{c}\text { Porsche } \\
\text { Panamera S }\end{array}$ & 104.34 & ICE & - & - & 5,1 & 204 & Porsche, 2015 \\
\hline Mercedes S 500 e lang & 109.777 & $\begin{array}{c}\text { PHE } \\
\text { V }\end{array}$ & 33 & $\begin{array}{l}\text { Charging station: } 1,9 \mathrm{~h} ; \text { Home } \\
\text { charging: } 4,1 \mathrm{~h}\end{array}$ & 5,2 & 65 & Mercedes, 2015 \\
\hline $\begin{array}{l}\text { Mercedes } \\
\text { S } 500 \text { lang }\end{array}$ & 109.777 & ICE & - & - & 4,8 & 192 & Mercedes 2015 \\
\hline $\begin{array}{l}\text { Volkswagen } \\
\text { Passat GTE }\end{array}$ & 44.25 & $\begin{array}{c}\text { PHE } \\
\text { V }\end{array}$ & 50 & $\begin{array}{l}\text { Regular charger: } 4: 15 \mathrm{~h} \text {; Wallbox: } \\
\qquad 2: 30 \mathrm{~h}\end{array}$ & 7,4 & 39 & $\begin{array}{c}\text { Volkswagen, } \\
2015\end{array}$ \\
\hline $\begin{array}{l}\text { Volkswagen } \\
\text { Passat TSI } \\
\text { BlueMotion }\end{array}$ & 40.025 & ICE & - & - & 6,9 & 143 & $\begin{array}{c}\text { Volkswagen } \\
2015 a\end{array}$ \\
\hline $\begin{array}{l}\text { VOLVO XC90 } \\
\text { T8 Twin } \\
\text { Engine }\end{array}$ & 77.8 & $\begin{array}{c}\text { PHE } \\
\text { V }\end{array}$ & 50 & $3,5 h-7,5 h$ & 5,6 & 49 & $\begin{array}{l}\text { VOLV } \\
\text { O, } \\
2015\end{array}$ \\
\hline $\begin{array}{c}\text { VOLVO XC90 } \\
\text { T6 AWD }\end{array}$ & 75.054 & ICE & - & - & 6,5 & 186 & $\begin{array}{l}\text { VOLV } \\
\text { O, } \\
2015\end{array}$ \\
\hline $\begin{array}{l}\text { Mercedes } \\
\text { C350 e }\end{array}$ & 50.961 & $\begin{array}{c}\text { PHE } \\
\text { V }\end{array}$ & 31 & $3,5 \mathrm{~h}$ & 5,9 & 54 & $\begin{array}{l}\text { Merce } \\
\text { des, } \\
2015 a\end{array}$ \\
\hline $\begin{array}{l}\text { Mercedes } \\
\text { C300 }\end{array}$ & 43.702 & ICE & - & - & 5,9 & 157 & $\begin{array}{l}\text { Merce } \\
\text { des, } \\
2015 a\end{array}$ \\
\hline
\end{tabular}

The $\mathrm{Co}_{2}$ emission is decisive in this study since it plays a $0 \%$ emission represent an ICE and an EV respectively. It was also moderating role in indicating the type of the car. A 100\% and a compulsory to introduce 2 other values for the PHEV to see the 
effect of a minimal amelioration on choices. Table 3 summarizes the attributes and their levels. For the utility computation, the lowest level (for example - 5\% for the price/ $50 \mathrm{~km}$ for electric range) was set to zero. Subsequently, all estimators are relative to an amelioration/augmentation (Table 3).

Table 3: Attributes and their shaping

\begin{tabular}{|c|c|}
\hline Attribute & $\begin{array}{l}\text { Levels (compared to preferred gaso- } \\
\text { line) }\end{array}$ \\
\hline Price & $\begin{array}{ll}\text { - } & -5 \% \\
\text { - } & 0 \% \\
\text { - } & +5 \% \\
\text { - } & +10 \%\end{array}$ \\
\hline Acceleration & $\begin{array}{ll} & -10 \% \\
\text { - } & 0 \% \\
\text { - } & +10 \%\end{array}$ \\
\hline Electric range $(\mathrm{km})$ & $\begin{array}{ll}\text { - } & 50 \text { (+ combustion) } \\
\text { - } & 250 \\
\text { - } & 500\end{array}$ \\
\hline $\begin{array}{l}\text { Charging time for } 50 \mathrm{~km} \\
\text { (in min) }\end{array}$ & $\begin{array}{ll}\text { - } & 10 \\
\text { - } & 30 \\
\text { - } & 120 \\
\text { - } & 300\end{array}$ \\
\hline $\mathrm{Co}_{2}$ emission reduction & $\begin{array}{ll}\text { - } & 0 \% \\
\text { - } & 70 \% \\
\text { - } & 80 \% \\
\text { - } & 100 \%\end{array}$ \\
\hline Subsidiary & $\begin{array}{ll}\text { - } & \text { No subsidiary } \\
\text { - } & \text { Non-monetary } \\
\text { - } & \text { Monetary }\end{array}$ \\
\hline
\end{tabular}

\section{Data Groundwork and Utility Computation}

\section{Coding data for utility computation}

In discrete choice models, preferences are represented by utility functions.

Mathematically:

$U_{i n}=U\left(Z_{i n}, S_{n}\right) ; \forall i \in J ; /\left\{\begin{array}{c}Z_{\text {in }} \text { attributes of alternativei faced by consumer } n \\ S_{n} \text { all relevant characteristics of consumer } n\end{array}\right.$

The decision rule is therefore explained by choosing the alternative $i$ with the highest utility among all options

$$
U_{i n}>U_{j n} ; \forall J \neq i, j \in J
$$

The utility can be therefore decomposed into:

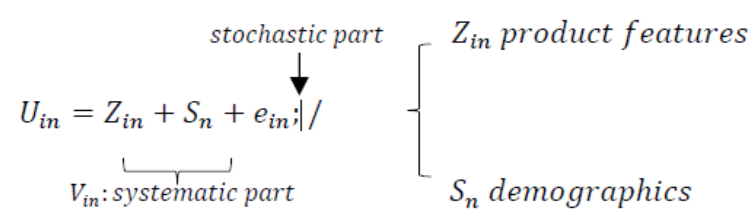

In case of two brands (easiest situation), the utility functions are expressed as follows:

$$
\begin{gathered}
U_{1 n}=V_{1 n}+e_{1 n} \\
U_{2 n}=V_{2 n}+e_{2 n}
\end{gathered}
$$

In this study, there are 3 products and the nonchoice option. Consequently, there are four utilities ( 1 for each choice). $U_{4 n}=\alpha_{4 n}+\beta_{1}$ Price $_{4 n}+e_{4 n}$ is set to zero to compute other utilities relative to the churning option since only difference in utility matters. In summary:

$$
\begin{gathered}
U_{1 n}=\alpha_{1 n}+\beta_{1} \text { Price }_{1 n}+\beta_{2 n} \text { Performance }_{1 n}+\ldots+e_{1} \\
U_{2 n}=\alpha_{2 n}+\beta_{1} \text { Price }_{2 n}+\beta_{2 n} \text { Performance }_{2 n}+\ldots+e_{2 n} \\
U_{3 n}=\alpha_{3 n}+\beta_{1} \text { Price }_{3 n}+\beta_{2 n} \text { Performance }_{3 n}+\ldots+e_{3 n} \\
U_{4 n}=0+\beta_{1} \text { Price } \text { Per }_{4 n}+\beta_{2 n} \text { Performance }_{4 n}+\ldots+e_{4 n}=0 \\
\text { The choice probability } \quad \text { (logit) is expressed by } \\
P_{n i}=\frac{e^{\left(\beta^{*} / \sigma\right)^{1 x} n i}}{\sum_{j} e^{\left(\beta^{*} / \sigma\right)^{1 x} n j}}
\end{gathered}
$$

However, the parameter is called scale parameter since all coefficients are scaled by $\frac{1}{\sigma}$ to reflect the variance of the unobserved part of the variables Train [26].

Subsequently only the ratio $\beta^{1}=\frac{\beta^{*}}{\sigma}$ is estimable not the

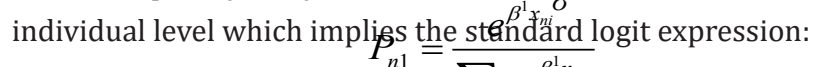

$$
=\frac{\sum_{j} e^{\beta^{1} x_{n j}}}{\sum}
$$

\section{Results interpretation}

Before running the model estimation, it was necessary to choose a convenient set of parameters. The Bayesian literature suggest the number of draws to be above 1000 draws to have efficient estimations RStan [68]. Additionally, using multiple chains is highly recommendable since having both various chains and sufficient draws allow the researcher to better judge the model and, see multiple chain convergence. It is important to mention that Stan uses a stochastic algorithm and so, the results will not be identical even with repetition using same parameters and starting values. In this case, after trying some combinations like 4 chains and 3000 iterations or 2 chains and 1000 iterations, the choice was to use 3 chains and 3000 draws due to a good mixture of computing time and results. The ggmcmc package was used because it provides multiple tools, so that their combination gives a precise indication of lack of convergence and, gives clues how to fix it:

\section{Formal}

- $\hat{R}$ : ggmcmc provides a potential scale reduction factor as one of the most valuable tool for chain convergence. $\widehat{R}$ relies on different chains for the same parameter through a comparison of both a within and a between chain variation. Therefore, it is expected to be close to 1 in the ideal case. The first 5 parameters are the price, performance in terms of acceleration, electric range, charging time and $\mathrm{Co}_{2}$ emission reduction respectively. 
Beta_mu [9] describes the subsidiary variable. The sequences appear to have mixed well. The estimated potential scale reduction factors $\hat{R} \sim 1$ for all the parameters and quantile of interest displayed (Figure 5).

- Gewecke z-scores: stresses the contrast between the begin and the last part of a chain. More precisely, the test is a frequentist comparison of the means. Subsequently, the result should lay between -2 and 2 (Fernandez, 2016). This area allows to check for problematic chains. In this case, it was difficult to identify the area only for these parameters since the model computes also coefficients at the individual level (243*9).

- $\quad$ N_eff is a random variable estimated from the simulation draws. The one with higher effective sample size has lower standard errors of the mean and more stable estimates. This choice guarantees the highest n_eff (Figure 5) values among all other alternatives (highest values here compared to pretests with 4 chains and 3000 iterations) (Figure 5).

\begin{tabular}{|c|c|c|c|c|c|c|c|c|c|}
\hline \multicolumn{10}{|c|}{$\begin{array}{l}\text { Inference for stan model: fed } 4 \text { fa } 288 \mathrm{cc} 4982 \mathrm{f} 79 \mathrm{bc} 480286 \mathrm{c} 23923 \text {. } \\
3 \text { chains, each with iter=3000; warmup=1000; thin=1: } \\
\text { post-warmup draws per chain=2000, total post-warmup draws }=6000 \text {. }\end{array}$} \\
\hline & mean & se_mean & sd & $2.5 \%$ & $25 \%$ & $50 \%$ & $75 \%$ & $97.5 \%$ & n_eff Rhat \\
\hline beta_nu [1] & 0.75 & 0.02 & 0.36 & 0.01 & 0.51 & 0.77 & 1.01 & 1.41 & 2341.01 \\
\hline beta_nu [2] & 0.46 & 0.01 & 0.23 & 0.00 & 0.30 & 0.46 & 0.62 & 0.89 & 2431.02 \\
\hline beta_nu [3] & 0.05 & 0.00 & 0.01 & 0.02 & 0.04 & 0.05 & 0.06 & 0.08 & 901.04 \\
\hline beta_nu [4] & -0.01 & 0.00 & 0.02 & -0.06 & -0.03 & -0.01 & 0.01 & 0.03 & 2811.02 \\
\hline beta_mu[5] & 1.12 & 0.19 & 0.52 & 0.06 & 0.77 & 1.14 & 1.49 & 2.09 & 71.19 \\
\hline beta_nu[9] & -0.24 & 0.00 & 0.03 & -0.31 & -0.27 & -0.24 & -0.22 & -0.18 & 5151.01 \\
\hline
\end{tabular}

Figure 5: Stan model output (car attributes).

\section{Histograms/density plots/ full and partial chain comparison}
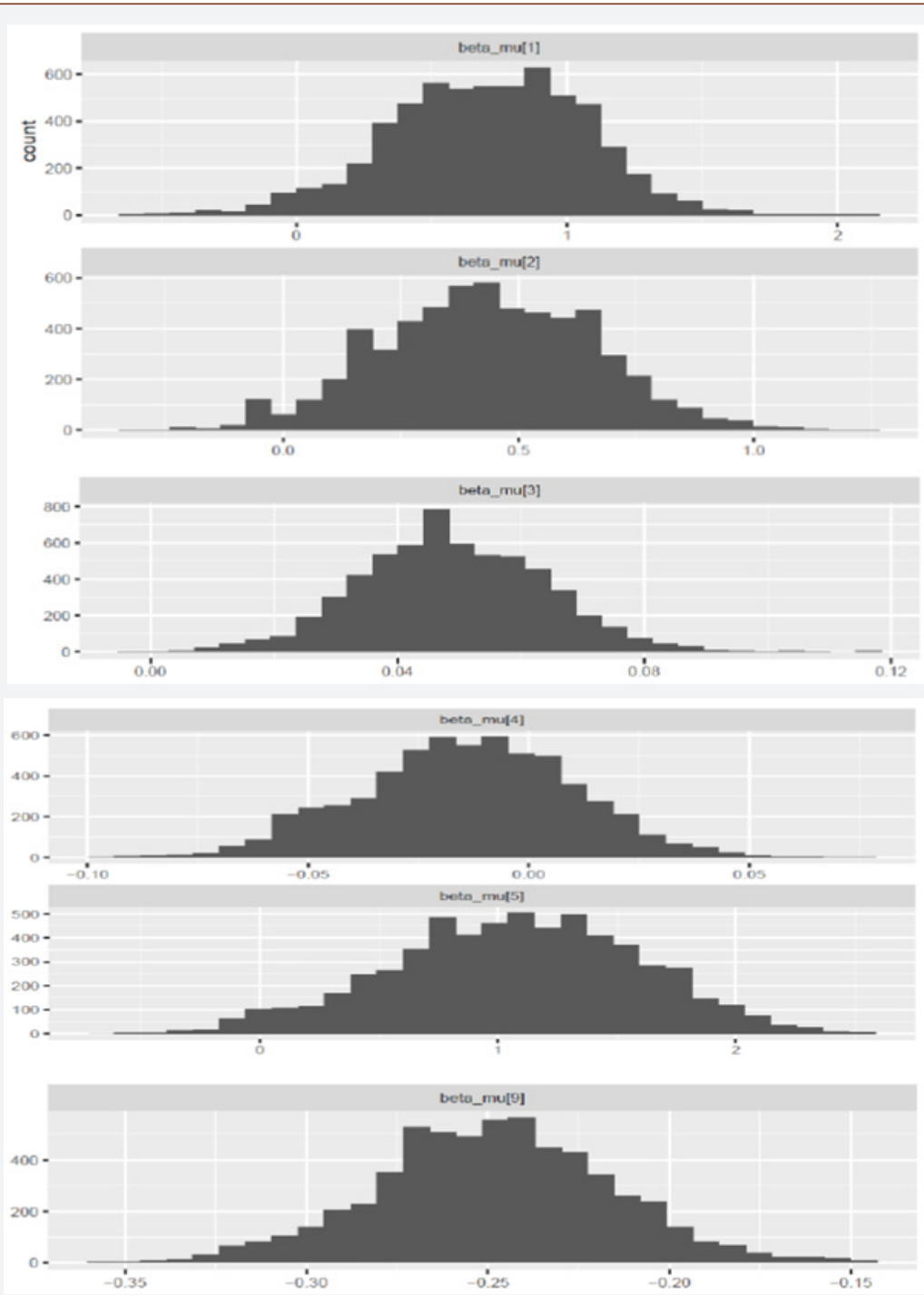

Figure 6: Stan model output (car attributes). 
Histograms present the posterior distribution and combine the values of all chains. Nonetheless, it is only a general view of the distribution and the posterior shape, not a convergence plot. The price histogram shows a bell-shaped distribution in the positive interval (Figure 6). This is consistent with the fundamentals of luxuries. Prosperous buyers are accepting expensive cars because they signalize high quality and exclusivity aspects. Furthermore, customers dedicate high budgets for the vehicle purchase since it is the best mean to project prosperity and status. In conclusion, luxury buyers are accepting soaring prices from favorite manufactures to enjoy the experience of driving their dream cars. This implies, that higher prices won't prevent clients from acquiring their favorite vehicle (other luxury values and features should be guaranteed). Besides, the majority were ready to pay between 5 and 10\% more to get a sophisticated vehicle from their favorite manufacturer. This is primary for the hole industry: first, it shows that the segment is characterized through a high loyalty level. Second, it indicates a market research deficiency. Numerous companies need to be more sophisticated and not only produce cars that meet customer needs, but a touch above (in all dimensions: functional \& hedonic). Primary is then an appropriate application of prestige pricing. In contradiction to previous investigations, expensiveness in the luxury car industry won't prevent clients to purchase their preferred car, it is more likely to enhance their interest. In summary, high prices are significantly related with key aspects such as quality, aesthetics, status and enjoyment (Figure 6).

Acceleration have also a positive distribution. This is consistent with the fundaments of luxury where functional dimensions are decisive. For instance, fast vehicles have improved features, quality and are more sophisticated. Sportiness in terms of acceleration makes the driving experience more enjoyable and pleasant. Subsequently, the hedonic component will increase, the luxuriousness feelings and the arousal level expand. Besides, the distribution of the range preferences is commonly positive which infers that prosperous consumers are preferring performed vehicles with a range comparable to combustion ones. Unlike some guesses like prosperous buyers have numerous cars and therefore, they can use another vehicle if the travel distance exceeds the battery capacity, this study shows the indispensability of large ranges in their DM. This is also consistent with the luxury definition as well as with the adoption theories where the new car should show, at least, similar (\& better) features as their status-quo. Subsequently, luxury buyers are used to higher standards and values which can't be disregarded or neglected. As long as manufacturers guarantee these performances and values, there is no reason for switching to competitors. Beta_mu [4] indicates the impact of extended charging time which is, as expected, mostly negative. However, some respondents were accepting longer charging processes which might be due to a limited usage (multicar) and/or to the limited concurrence at this time. Also, the trendiness and the nature of some luxury buyers who are innovative and seek primary novel goods might be a good clarification of this partial preference. For example, some clients are more flexible and can use another vehicle if the charging time gets longer. However, this should not exceed a certain time window. Hence, luxury manufacturers have the defy to develop new techniques and strategies that smooth a strong presence in the new market.

Regarding the reduction of $\mathrm{Co}_{2}$ emission (beta_mu[5]), the output shows the highest respondent preferences. The appearance of environmental friendly customers such as the LOHAS and the millennials strengthens the preference for ecological cars. Moreover, more and more traditional Luxury buyers are getting aware of environmental issues. This consciousness results in an adaption behavior like acquiring "green" goods. Unlike the results presented by various researchers like Davies et al. [61], prosperous customers show a high consciousness about environmental issues without snubbing the benefits of luxuries. Regardless of their motivations and incentives (intrinsic vs. extrinsic; ecology vs. materialism) all customers show a high preference for "green" driving. Accordingly, ignoring ecology and sustainability in the high-end market outcomes a total disaster for producers. Therefore, finding the right recipe including ecology and luxury characteristics such as enjoyment is a key for success in the future market. Also, the data shows immense opportunities for established firms through a strong existing loyalty and deep brand relationships (love, attachment, etc.) to maintain customers and good market shares. The last estimated parameter is the preference for subsidiary (nonand monetary). Beta_mu[9] is negatively bell-shaped distributed. Studies of Davies et al. [61], Jannsson [58] showed the importance of these incentives in the mass market. Customers were interested in EVs primary due to cost savings (maintenance) and other financial incentives (tax exemption, etc.). However, prosperous buyers don't care about the peripheral governmental advantages they can get through purchasing ecological products. For instance, using bus lines, free parking or tax exemption don't incentive them and are not decisive in the decision- making. This is consistent with the understanding of luxury which relies on exclusivity, rarity, enjoyment and extraordinariness. Consequently, unlike the mass market, wealthy consumers fully ignore these measures. Subsequently, all the hypothesis are confirmed and deep-rooted.

The density plot has the advantage that the researcher can compare the chains and if they converged in a similar space due to distinct colors. the density plots for price and Performance estimations show a high chain convergence and that all three chains converged in the same interval. This is the case for all other attributes which, due to limited space, are not included here. In the same context of overlapping densities, ggmcmc allows to compare the last part of the chain (last 10\%) with the whole chain. Commonly, they should be sampling in the same direction, meaning, the overlapped densities should be similar. Continuing with the first 2 attributes, price and performance, the last part has generally the same tendency as the whole chain, especially for $2^{\text {nd }}$ and $3^{\text {rd }}$ chains (Figure 7).

All other attributes have similar characteristics. 


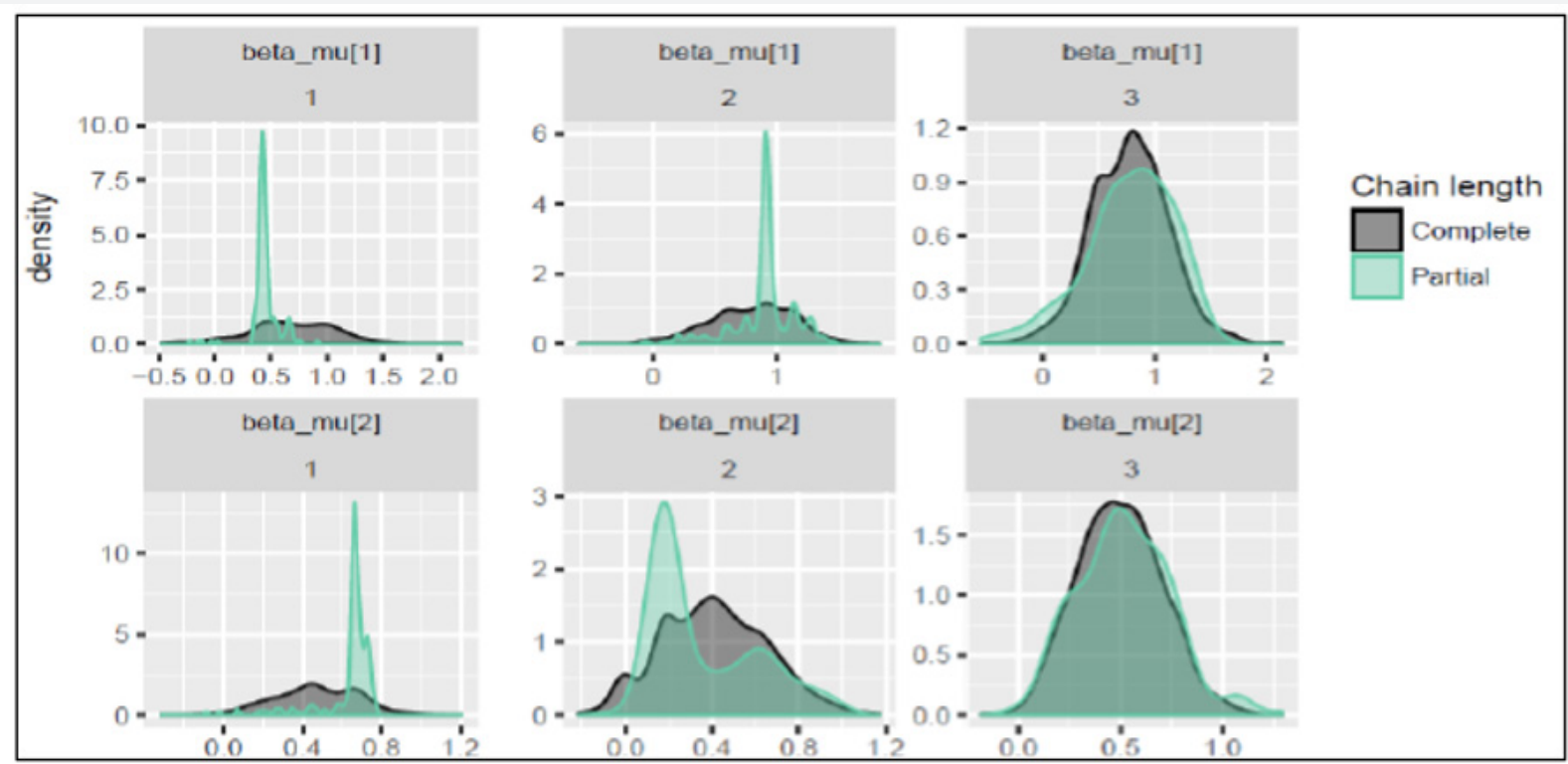

Figure 7: Partial vs. full chain comparisons.

\section{Trace plots/running means/autocorrelations}

Trace plots are an essential part for evaluating convergence and diagnostic chain issues. It allows to see the time series of the sampling process. Important, is to have a random walk and not a tendency which implies a lack of convergence. In this case, all three chains have mixed very well and follow a random sampling way (Figure 8). The distinct colors allow the between chain comparison. Another way to judge the efficiency is the speed of the chain convergence, a plot with the running means. This is helpful to study the within chain convergence issues. The outcome is as expected, a horizontal line that quickly approaches the global mean, and all chains have comparable means (Figure 9). Furthermore, the autocorrelation plot of the chains is a powerful tool to assess the quality of the chain. The outcome is a bar in the first lag (at 1) and converges to zero (Figure 10). Most of the chains seem to have a good behavior and, so guarantee good estimations. However, autocorrelation is not definitively a bad signal such as lack of convergence might be an indicator of chain/ parameter misbehavior. It also indicates that a chain needs more time to converge than others. In conclusion, all chains for the 6 car attributes have converged very well and the formal diagnostic tools ( $\hat{R}$, Gewecke z-score) show efficient results. Accordingly, luxury car buyers (independent of number of cars) are very interested in EVs and are willing to pay considerable amounts for performance in terms of acceleration and electrical range. Furthermore, they prefer lower $\mathrm{Co}_{2}$ emission which implies a high consciousness level. This is consistent with current researches which highly recommend ecology and sustainability in luxuries, even if the customer doesn't acclaim it openly $[1,3,6,69,70]$. Subsequently, ignoring such aspects would prevent clients to buy their favorite brands and so, voluntary churn. Also, long charging times are less preferred despite that clients come from multicar households. Luxury electric vehicle producers, should perform both battery capacity and efficiency. These are crucial features toward achieving competitive advantages. The finding is primary for manufacturers and, especially market leaders such as Daimler, Porsche, Ferrari etc. since it shows a high customer loyalty level. However, finding a good mixture of indulgence, trendiness in terms of ecology and functional values is the recipe for a lasting success. Most prosperous clients show a high to absolute loyalty. There is no reason for churning and switching to competitors if the favorite car fabricator fulfills their wishes and assures luxury values such as exclusivity (soaring prices up to $10 \%$ compared to combustion cars) and tall quality (acceleration \& aestetics), and an ecological component (reduction of $\mathrm{Co}_{2}$ emission) (Figure 8-10).

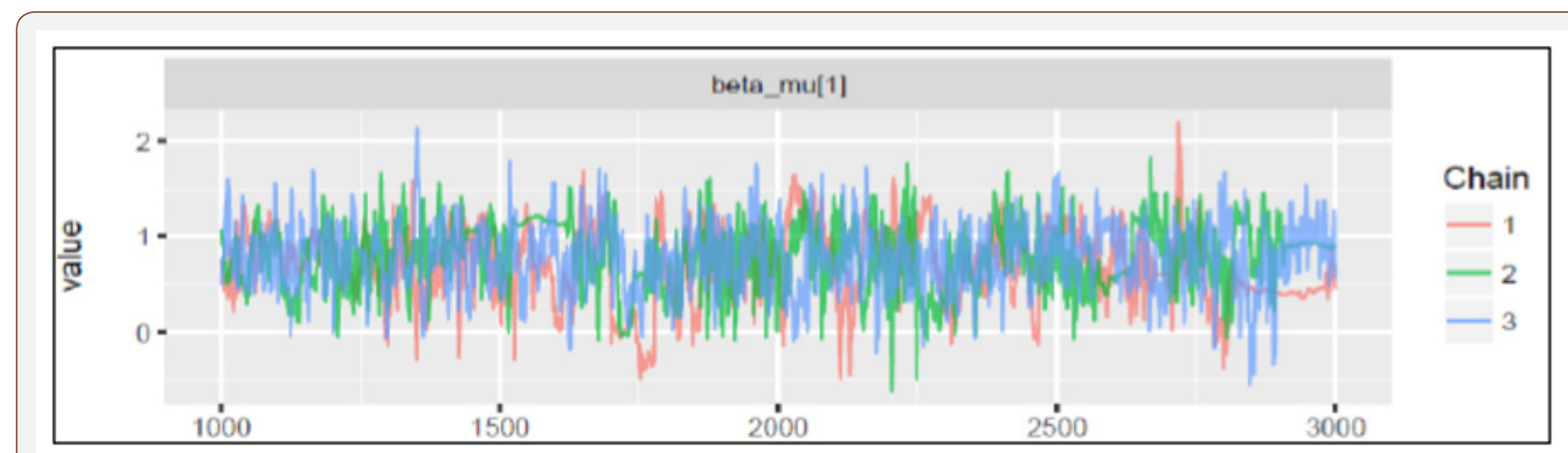

Figure 8: Trace plot (Price estimation). 


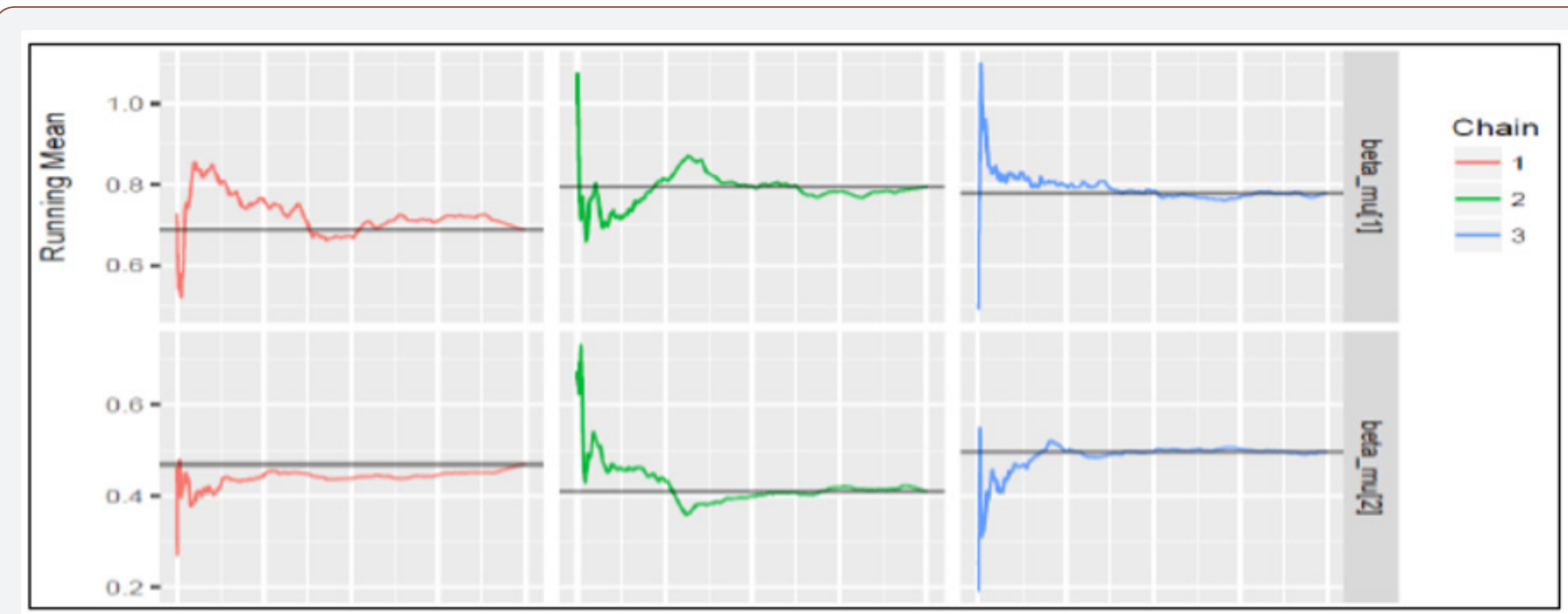

Figure 9: Running means (Price and Performance estimations).

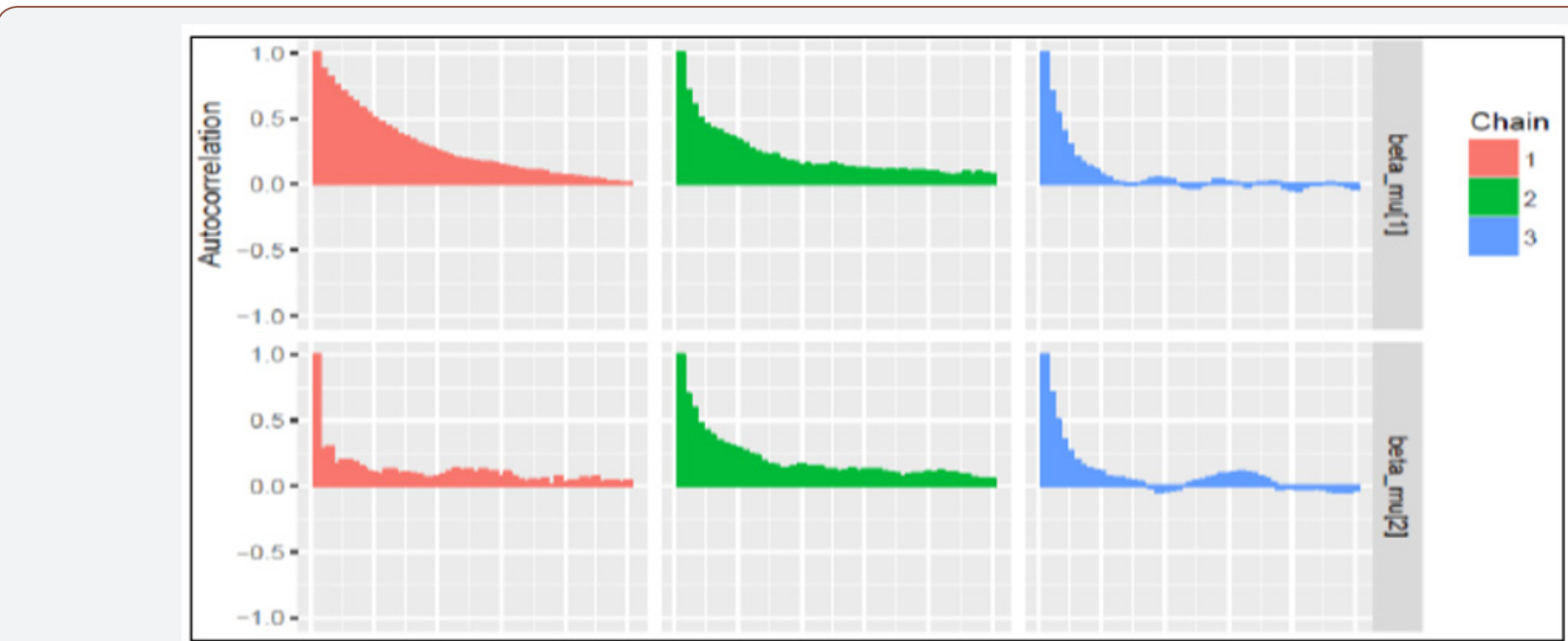

Figure 10: Autocorrelation plots (Price and Performance estimations).

Afterwards, the introduction of consumer characteristics such as Demographics and measures of both environmental friendliness and materialism is beneficial to get consistent and reliable estimations. The model computes coefficients on the individual level for every car type (EV,PHEV \& ICE). To this issue, a Caterpillar plot is drawn to get better elucidations since it shows the general pattern of the results through ordering the Variables by effect magnitude. The result shows high effect of the income for all car types. $\alpha_{\text {wage } E V} \sim \alpha_{\text {wage } E V} \sim \alpha_{\text {wage } E V}$. Surprisingly, is that all variables have similar influence and appreciation among all three car variations $\alpha_{i, E V} \sim \alpha_{i, \text { PHEV }} \sim \alpha_{i, I C E}$. This means, there is no clear preference pattern or big differences among luxury customers that can clearly predict their choices for a concrete car type. This might be due to the choice situations where the randomly presented attribute levels don't favorize one type over the other. This might be due to the lack of specific brands since we didn't introduce specific manufacturers in the survey. The generalizability of the study as well as the diversity of the brands and their values are major factors. Nonetheless, the output recognizes the reduction of $\mathrm{Co}_{2}$-emission as highest and most preferable attribute which, implicitly means $\alpha_{i, E V}>\alpha_{i, \text { PHEV }}>\alpha_{i, \text { ICE }}$ (under the assumption that other luxury values are guaranteed). Toward testing this finding, a cluster analysis would be an appropriate tool since the model estimates coefficients on the individual level (each person on each car attribute). Explicitly, a Model based approach because it assumes a variety of data models and applies maximum likelihood estimation and Bayes criteria to identify the most likely model and number of clusters. Specifically, the Mclust (Figure 11) function in the 'mclust' package in R selects the optimal model according to BIC for EM initialized by hierarchical clustering for parameterized Gaussian mixture models (Package 'mclust', [71]. The output is consistent with the Caterpillar plot. It suggests two groups which are unbalanced (around 88\% of respondents in the first group). Moreover, comparing the average values for each cluster on every vehicle attribute, shows similar preferences with a minimal difference in their intensities. For example, both groups prefer expensive performed cars but the first one has tougher requirements for acceleration, electric range and $\mathrm{Co}_{2}$ emission reduction. However, the second group is somehow agiler in dealing with extended charging times and with 
the introduction of subsidiaries [72-80]. In a further step, we tried to both identify churners as well as the specific cases where they decided not to buy (Figure 12) [81-86]. The decision was to focus on people who picked up ecological products (PHEV \& EV) less than $50 \%$ (in 5 cases there were only combustion cars) among all 12
(17-5) choice situations [87-95]. The analysis confirms that those were churning due to a lack of quality aspects such as lower range and longer charging time. They built the second cluster with the tougher quality requirements [96-100] (Figure 11,12).

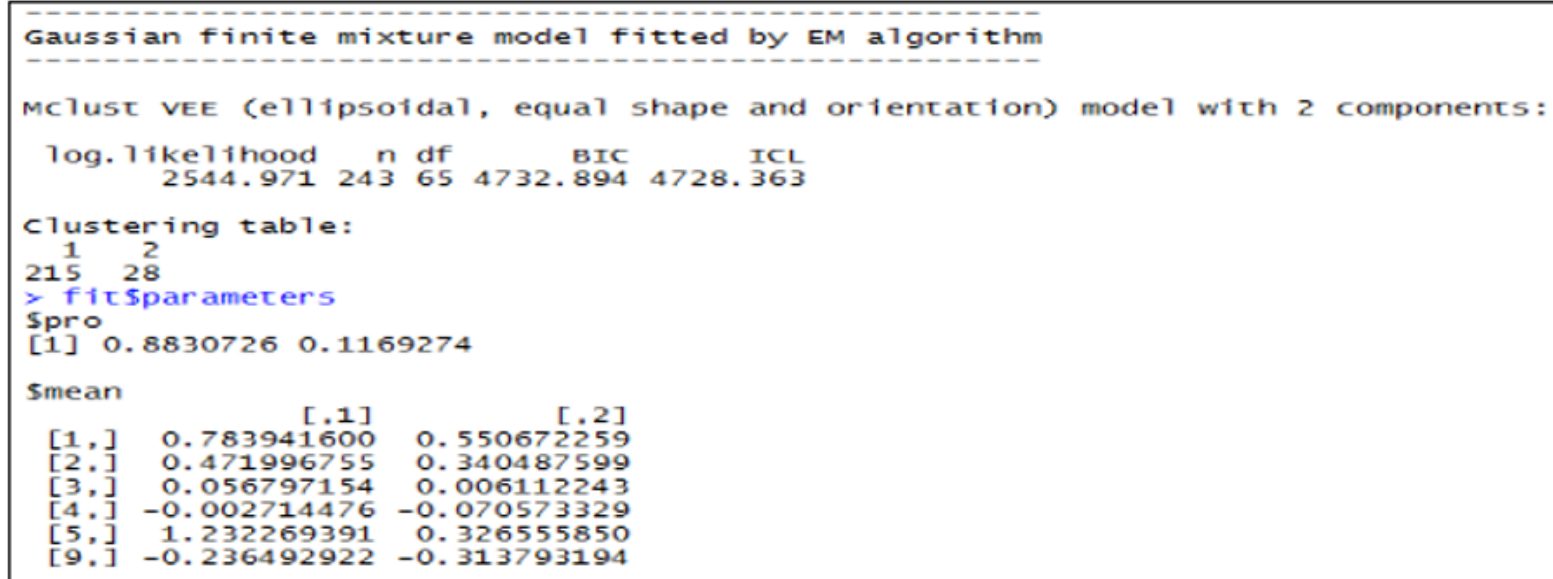

Figure 11: Clustering using 'mclust' package.

\section{Distribution of Risky customer}

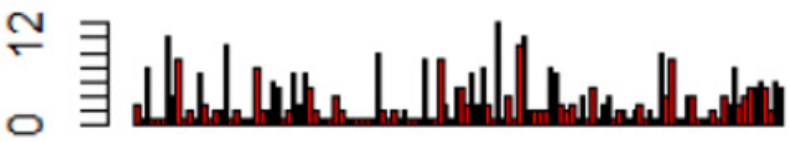

\section{$10 \quad 43 \quad 75 \quad 117 \quad 169 \quad 216$}

\section{Customer ID}

Figure 12: Identification of churners.

\section{Conclusion}

This work investigates the willingness to buy luxury EVs from the favorite car manufacturers. Furthermore, it aims to model the churn risk if producers ignore important aspects such as sustainability and ecology. Concrete brands were ignored due to the difficulty to, first cover all luxury car manufacturers in one study and second, to get sufficient luxury customers for each manufacturer and so, to get a representative sample. Also, this allows to get a generalizable model. To conclude, prosperous buyers are generally environmentally friendly and, are therefore ready to adapt their behavior in a conscious way. However, spending enormous amounts on green products should guarantee some luxury benefits such as enjoyment and exclusiveness. The study shows that regardless of the individual ecology/materialism level, all customers are strongly preferring lower $\mathrm{Co}_{2}$ emission. Moreover, acceleration and soaring prices were significant factors influencing the decision making. This is consistent with the fundamentals of luxury in terms of high quality, high price, extraordinariness, etc. Also, the cluster analysis using coefficients for both individual and alternative specific variables show high preference similarity among all luxury customers. The finding is primary for established luxury car manufacturers to keep their customers loyal and, to guarantee a leading market position. Producing EVs in the highend segment has enormous potential and a huge effect on firms' success and survive. Nevertheless, not only product and customer' characteristics are relevant factors influencing the decisionmaking and, subsequently the loyalty, but also the brand value is significant. A Ferrari as an example offer their owners completely different values and sensations than a Mercedes, a BMW or even a Porsche, and vice versa.

This massive acceptability for luxury ecological automobiles might also originate from the nature of prosperous buyers who are constantly seeking for trendy and new extravagant products that keep them privileged and guarantee a high arousal level. Additionally, such green products are well accepted and gladly seen. Accordingly, a high social status. Concerning churners, depending on the brand value and strength, their departing might be considered a consumption break. This could only be the case for some leading firms and under certain assumptions (update, catch up. Superiority and preeminence in short time). According 
to Nelson and Meyvis [55], interrupting a pleasant experience reduces adaptation (familiarity) which implies a tall arousal level. Consequently, it makes the consumption experience more enjoyable after that break. Analogous, if customers enjoyed their current luxury car and switch to competitor just for change and not due to remarkably superior features, they are more likely to have an unpleasant experience with the new vehicle. The change is to some extent the break. Afterwards, churners will identify the superiority of their favorite manufacturers, appreciate it more, and subsequently reemerge. Their consumption experience should then be more enjoyable than before the intermission. However, if the churn is purely because of significant minor quality aspects (second group with tougher requirements), they are less likely to come back, especially if the new brand pleasingly fulfill their needs.

\section{Acknowledgement}

None.

\section{Conflict of Interest}

No conflict of interest.

\section{References}

1. Bendell J, Kleanthous A (2007) Deeper Luxury: Quality and Style When the World Matters.

2. Kapferer JN (2010) The new strategic brand management: creating and sustaining brand equity long term ( $4^{\text {th }}$ ed.). Kogan Page, London, UK.

3. Kapferer JN, Michaut A (2014) Is Luxury Compatible with Sustainability? Luxury Consumers Viewpoint. Journal of Brand Management 21(1): $1-22$

4. Dubois B, Laurent G (1994) Attitudes Towards the Concept of Luxury: an Exploratory Analysis. AP-Asia Pacific Advances in Consumer Research. Joseph A Cote, Siew Meng Leong, Provo (Eds.), UT: Association for Consumer Research, pp. 273-278.

5. Dubois B, Czellar S, Laurent G (2005) Consumer Segments Based on Attitudes Toward Luxury: Empirical Evidence from Twenty Countries. Marketing Letters 16(2): 115-128.

6. Wiedmann KP, Hennings N, Siebels A (2007) Measuring Consumers Luxury Value Perception: A Cross-Cultural Framework. Academy of Marketing Science 7(7): 1-20.

7. Hennigs N, Wiedmann KP, Klarmann C, Behrens S (2013) Sustainability as Part of the Luxury Essence: Delivering Value through Social and Environmental Excellence. Journal of Corporate Citizenship 52(11): 2535 .

8. Pollak RA (1970) Habit Formation and Dynamic Demand Functions. Journal of Political Economy 78(4): 745-763.

9. Garcia Torres MA (2009) Consumer Behavior: Evolution of Preferences and The Search for Novelty. United Nations University, Tokyo, Japan.

10. Schmitt B, Brakus JJ, Zarantonello L (2015) From experiential psychology to consumer experience. Journal of Consumer Psychology 25(1): 166171.

11. Cretu AE, Brodie RJ (2007) The influence of brand image and company reputation where manufacturers market to small firms: A customer value perspective. Industrial Marketing Management 36(2): 230-240.

12. Zaichkowsky JL (1985) Measuring the Involvement Construct. Journal of Consumer Research 12(3): 341-352.

13. Thomson M, MacInnis D, Park C (2005) The ties bind: Measuring the strength of consumers emotional attachments to brands. Journal of Consumer Psychology 15(1): 77-91.

14. Aaker J (1997) Dimensions of Brand Personality. Journal of Marketing Research 34(3): 347-356.
15. Graeff TR (1997) Consumption situations and the effects of brand image on consumers brand evaluations. Psychology and Marketing 14(1): 4970

16. Salinas EM, Perez JMP (2009) Modeling the brand extensions influence on brand image. Journal of Business Research 62(1): 50-60.

17. Aaker J (1999) The Malleable Self: The Role of Self-Expression in Persuasion. Journal of Marketing Research 36(1): 315-328.

18. Grohmann B (2009) Gender dimensions of brand personality. Journal of Marketing Research 46(1):105-119.

19. Dusenberry JS (1952) Income, Saving, and the Theory of Consumer Behavior. Harvard University Press: Cambridge, US.

20. Pollak RA (1970) Habit Formation and Dynamic Demand Functions. Journal of Political Economy 78(4): 745-763.

21. Lancaster KJ (1966) A New Approach to Consumer Theory. The Journal of Political Economy 74(2): 132-157.

22. Hawkins SA, Hoch SJ (1992) Low-involvement learning: Memory without evaluation. Journal of Consumer Research 19(2): 212-225.

23. Malar L, Krohmer H, Hoyer WD, Nyffenegger B (2011) Emotional Brand Attachment and Brand Personality: The Relative Importance of the Actual and the Ideal Self. Journal of Marketing 75(4): 35-52.

24. Berry S, Levinsohn J, Pakes A (1995) Automobile Prices in Market Equilibrium. Econometrica 63(4): 841-890.

25. Brwonstone D, Bunch DS, Train K (2000) Joint mixed logit models of stated and revealed preferences for alternative-fuel vehicles. Transportation Research Part B: Methodological 34(5): 315-338.

26. Train K (2002) Discrete Choice Methods with Simulation. National Economic Research Associates: Cambridge University Press: Cambridge, UK.

27. Alba J, Hutchinson JW (1987) Dimensions of Consumer Expertise. Journal of Consumer Research 13(4): 411-454.

28. Johar GV, Pham MT (1999) Relatedness, prominence, and constructive sponsor identification. Journal of Marketing Research 36(3): 299-312.

29. MacInnis DJ, Jaworski BJ (1989) Information processing from advertisements: towards an integrative framework. J Mark 53(4): 1-23.

30. Hadden H, Tiwari A, Roy R, Ruta D (2007) Computer assisted customer churn management: State-of-the-art and future trends. Computers and Operations Research 34(10): 2902-2917.

31. Liu DR, Shih YY (2004) Hybrid approaches to product recommendation based on customer lifetime value and purchase preference. The Journal of System and Software 77(2): 181-191.

32. Kim HS, Yoon CH (2004) Determinants of subscriber churn and customer loyalty in the Korean mobile telephony market Determinants of subscriber churn and customer loyalty in the Korean mobile telephony market. Telecommunications policy 28(9-10): 751- 765.

33. Kim M, Park JE, Dubinsky AJ, Chaiy S (2012) Frequency of CRM implementation activities: a customer-centric view. Journal of Services Marketing 26(2): 83-93.

34. Burez J, Van den Poel D (2007) CRM at a pay-TV company: Using analytical models to reduce customer attrition by targeted marketing for subscription services. Expert Systems with Applications 32(2): 277-288.

35. Van den Poel D, Lariviere B (2004) Customer attrition analysis for financial services using proportional hazard models. European Journal of Operational Research 157(1): 196-217.

36. Bower JB, Christensen CM (1995) Disruptive Technologies: Catching the Wave. Harvard Business Review 43-53.

37. Bower JB, Christensen CM (1995) Disruptive Technologies: Catching the Wave. Harvard Business Review 43-53.

38. Adner R (2002) When are technologies disruptive? a demand-based view of the emergence of competition. Strat Mgmt J 23(8): 667-688.

39. Wei C, Chiu I (2002) Turning telecommunications call details to churn prediction: a data mining approach. Expert Systems with Applications 23(2): 103-112. 
40. Albert JH, Chib S (1993) Bayesian analysis of binary and polychotomous response data. Journal of the American statistical Association 88(422): 669-679.

41. McCulloch R, Rossi E (1994) An exact likelihood analysis of the multinomial probit model. Journal of Econometrics 64(1-2): 207-240.

42. Cameron AC, Trivedi PK (2005) Microeconometrics Methods and Applications. Cambridge CB2 2RU, UK.

43. Bain \& Company (2016) Luxury Goods Worldwide Market Study.

44. Hidrue MK, Parsons GR, Kempton W, Gardner MP (2011) Willingness to pay for electric vehicles and their attributes. Resource and Energy Economics 33(3): 686-705.

45. Petschnig M, Heidenreich S, Spieth P (2014) Innovative Alternatives Take Action - Investigating Determinants of Alternative Fuel Vehicle Adoption. Transportation Research Part A: Policy and Practice 61: 6883.

46. Dubois B, Czellar S, Laurent G (2005) Consumer Segments Based on Attitudes Toward Luxury: Empirical Evidence from Twenty Countries. Marketing Letters 16(2): 115-128.

47. Heine K (2012) The Concept of Luxury Brands.

48. Langer D, Heil O (2013) Luxury Marketing \& Management. Center for Luxury Research: Mainz, Germany.

49. Garcia Torres A (2004) Consumer Behavior: utility maximization and the seek for novelty. Maastricht University, Netherlands.

50. Johnson Laird PN, Girotto V, Legrenzi P (2004) Reasoning from inconsistency to consistency. Psychological Review 111(3): 640-661.

51. Legrenzi P, Umita C (2011) Neuromania: On the Limits of Brain Science. Oxford University Press: Oxford, UK.

52. Hebb DO (1955) Drives and the C. N. S. (conceptual nervous system). Psychological Review 62(4): 243-254.

53. Berlyne DE (1970) Novelty, complexity, and hedonic value. Percept \& Psychophys 8(5): 279-286.

54. Berlyne DE (1960) Conflict, arousal, and curiosity. New York, US.

55. Nelson LD, Meyvis T (2008) Interrupted Consumption: Disrupting Adaptation to Hedonic Experiences. Journal of Marketing Research 45(6): 654-664.

56. Vigneron F, Johnson LW (1999) A review and a conceptual framework of prestige-seeking consumer behavior. Academy of Marketing Science Review (1): 1-18.

57. Jansson J (2011) Consumer eco-innovation adoption: assessing attitudinal factors and perceived product characteristics. Bus Strategy Environ. 20(3): 192-210.

58. Leibenstein Harvey (1950) Bandwagon, Snob and Veblen Effects in the Theory of Consumer Demand. Quarterly Journal of Economics 64(2): 183-207.

59. Meffert H, Lasslop I (2004) Luxusmarkenstrategie. Bruhn M (Ed.), Handbuch Markenführung, Wiesbaden, Germany.

60. Ward D, Chiari C (2008) Keeping Luxury Inaccessible. European School of Economics: MRPA (Munich Personal RePEc Archive).

61. Davies IA, Lee Z, Ahonkhai I (2012) Do Consumers Care About Ethical Luxury? Journal of Business Ethics 106(1): 37-51.

62. Kndall J (2010) Responsible luxury: A report on the new opportunities for business to make a difference. CIBJO (Confederation internationale de la Bijouterie, Joaillerie et Orfevrerie): The World Juwellery.

63. Bendell J (2012) Elegant disruption: how luxury and society can change each other for good. Asia Pacific Center for Sustainable Enterprise Queensland.

64. Haws KL, Winterich KP, Naylor RW (2010) Seeing the World Through Green-Tinted Glasses: Motivated Reasoning and Consumer Response to Environmentally Friendly Products. Journal of Macromarketing 5(2): 18-39.
65. Eastman JK, Goldsmith RE, Flynn LR (1999) Status Consumption In Consumer Behavior Theory: Scale Development And Validation. Journal of Marketing Theory and Practice 7(3): 41-52.

66. Bower JL, Christensen CM (1995) Disruptive Technologies: Catching the Wave. Harvard Business Review 73(1): 43-53.

67. Christensen CM (1997) The Innovator's Dilemma: When New Technologies Cause Great Firms to Fail. Boston, US.

68. Rstan (2017) Found under: https://cran.r-project.org/web/packages/ rstan/vignettes/rstan.html.

69. Hoffman MD, Gelman A (2014) The No-U-Turn Sampler: Adaptively Setting Path Lengths in Hamiltonian Monte Carlo. Journal of Machine Learning Research 15: 1593-1623.

70. Cvijanovich M (2011) Sustainable Luxury: Oxymoron? Lecture in Luxury and Sustainability.

71. Package mclust (2017) Gaussian Mixture Modelling for Model-Based Clustering, Classification, and Density Estimation. Found under: https://cran.r-project.org/web/packages/mclust/mclust.pdf.

72. Allen CT, Madden TJ (1985) A Closer Look at Classical Conditioning. The Journal of Consumer Research 12(3): 301-315.

73. Barry TE, Howard DJ (1990) A Review and Critique of The Hierarchy of Effects in Advertising. International Journal of Advertising 9(2): 98-111.

74. BMW (2015) Found under: http://www.bmw.de/de/neufahrzeuge/ bmw-i.html.

75. Feinberg R (1986) Credit Cards as Spending Facilitating Stimuli: A Conditioning Interpretation. Journal Of Consumer Research 13(3): 348356.

76. Fernandez IM (2019) Using the ggmcmc package.

77. Gelman A, Jakulin A, Pittau MG, Su YS (2008) A Weakly Informative Default Prior Distribution for Logistic and other Regression Models. The Annals of Applied Statistics 2(4): 1360-1383.

78. Langer EJ (1983) The Psychology of Control. Behavioral and Cognitive Psychotherapy 14(2): 311.

79. Lewis A, Webley P, Furnam A (1995) The New Economic Mind, 2, Prentice Hall.

80. Marschak J (1960) Binary Choice Constraints on Random Utility Indicators. K Arrow (Ed.), Stanford Symposium on Mathematical Methods in the Social Sciences.

81. Marshall A (1890) Principles of Economics. In Westing HJ, Albaum G (1975) Modern Marketing Thought 3, Collier Macmillan Publishers.

82. McFadden D (1974) Conditional logit analysis of qualitative choice behavior.

83. McFadden D (1978) Econometric Models of Probabilistic Choice.

84. McFadden D (1987) Regression-based specification tests for the multinomial logit model. Journal of Econometrics 34(1-2): 63

85. Pachauri M (2001) Consumer Behavior: A Literature Review. The Marketing Review 2(3): 319-355.

86. Peter JP, Nord WR (1982) A Clarification and Extension of Operant Conditioning Principles in Marketing. Journal of Marketing 46(3): 102107.

87. Polson N, Scott J (2011) Shrink globally, act locally: Sparse Bayesian regularization and prediction. JM Bernardo, MJ Bayarri JO Berger, AP Dawid, D Heckerman, et al. (Eds.), Oxford University Press: Oxford, UK.

88. Skinner BF (1938) The behavior of organisms. New York, USA.

89. Skinner BF (1953) Science and human behavior. New York: MacMillan, USA.

90. Stan Development Team (2017) Found under: http://mc-stan.org/ users/documentation/.

91. Tesla $(2015,2017)$ Found under: http://www.Tesla.com. 
92. Thorndike EL (1911) Animal Intelligence: Experimental Studies. Macmillan: New York, USA.

93. Train K, McFadden D (1978) The goods-leisure tradeoff and disaggregate work trip mode choice models. Transportation Research 12(5): 349353.

94. Train K, McFadden D, Ben Akiva M (1987) The demand for local telephone service: A fully discrete model of residential calling patterns and service choice. Rand Journal of Economics 18(1): 109-123.

95. Train K, McFadden D, Goett A (1987) Consumer attitudes and voluntary rate schedules for public utilities. Review of Economics and Statistics 69(3): 383-391.
96. Train K, Ben Akiva K, Atherton T (1989) Consumption patterns and selfselecting tariffs. Review of Economics and Statistics 71(1): 62-73.

97. Volkswagen $(2015,2016,2017)$

98. Volvo $(2015,2016,2017)$

99. Watson JB, Raynier R (1920) Conditioned emotional reactions. J. exp. Psychol 3(1): 1-14.

100. Westing JH, Albaum GS (1975) Modern marketing thought. University of Michigan: Macmillan, UK. 